\title{
Keberlanjutan Keberkahan Pada Komunitas Bisnis Kuliner: CDA
}

\author{
Tubagus Chaeru Nugraha1*, Davidescu Cristiana ${ }^{1}$ \\ ${ }^{1}$ Departemen Linguistik, Universitas Padjadjaran, Bandung, Indonesia
}

\section{ARTICLE INFO}

Keywords

Keberlanjutan, keberkahan, bisnis, Culinary Business

Community

\section{*Correspondence \\ t.chaeru@unpad.ac.id}

\section{Article History}

Received 18 November 2018

Accepted 31 Maret 2019

Published online 2 April 2019

\begin{abstract}
Tujuan penelitian ini adalah mendeskripsikan nilai-nilai religius sebagai sebab keberkahan bisnis. Orientasi bisnis biasanya hanya pada tujuan profit, benefit, pertumbuhan, dan keberlanjutan/ keberlangsungan. Dalam artikel ini diungkapkan konsep keberlanjutan bisnis yang berkah. Data diambil dari komunitas bisnis kuliner sebagai contoh empiris yang terdapat di kabupaten Bandung, kecamatan Cileunyi. Dalam penelitian ini digunakan metode deskriptif analisis. Agar hasil penelitiannya akurat, maka ditempuh dalam tiga langkah. Pertama, penyediaan data dengan metode simak-cakap dengan teknik kuisioner dan wawancara. Kedua, metode analisis yang digunakan secara eklektik antara Critical Discourse Analysis (CDA) pada tataran makro dan analisis prosentase. Ketiga, hasil analisis disajikan dalam tabel dan diberikan penjelasan secara deskriptif pada istilah-istilah ekonomi berbasis nilai-nilai religius. Nilai-nilai religious penyebab keberkahan adalah keimanan dan ketaqwaan. Dalam AlQur'an ada empat tema 'keberkahan', yaitu: (1) Mengimani Al-Qur'an dan mengamalkannya; (2) semua tempat orang yang beriman-bertaqwa, dan saling mendoakan; (3) Mu'jizat para Nabi; dan (4) mengikuti Sunnatu Allah. Rekomendasi dalam penelitian ini adalah perlunya revitalisasi nilai-nilai religious dalam aplikasi bisnis di masyarakat kabupaten Bandung, antara lain pada komunitas bisnis Cipacing, Cileunyi.
\end{abstract}

The purpose of this study is to describe religious values as a factor of business blessing. Business orientation is usually only for profit, benefit, growth, and sustainability goals. In this article, the concept of business sustainability is revealed. The data is collected from the culinary business community as an empirical example found in Bandung regency, Cileunyi district. This study also applies descriptive analysis method. In order to have accurate results, the steps of method are conducted in three steps. First, the provision of data with the method of conversation with questionnaire and interview techniques. Second, the analytical method used eclectically between Critical Discourse Analysis (CDA) at the macro level and percentage analysis. Third, the results of the analysis are presented in a table and given a descriptive explanation on economic terms based on religious values. The religious values that cause blessing are faith and devotion. In Qur'an there are four themes of 'blessing', namely: (1) Believing in Qur'an and practicing it; (2) all places are faithful, and pray for one another; (3) Miracles of the Prophets; and (4) following the Sunnatu Allah. The recommendation in this study is the need to revitalize religious values in business applications in Bandung regency community, including business community in Cipacing, Cileunyi.

\section{PENDAHULUAN}

Konsep dasar pembangunan berkelanjutan menurut Kates (2018) adalah memenuhi kebutuhan masa kini tanpa mengorbankan generasi yang akan datang dalam pemenuhan kebutuhannya. Dengan kata lain, pembangunan berkelanjutan tetap mempertahankan kelestarian lingkungan alam, sosial, dan budaya. Masalahnya, dimensi keberlanjutan sosial dan budaya adakalanya dianggap sebagai kendala dalam pembangunan . Berdasarkan ringkasan penelitian Chiu (2004), menurutnya ada tiga perbedaaan dalam memahami konsep keberlanjutan social (social sustainability), pertama (1) Development-oriented (2) Environment-oriented, (3) People-oriented. Ketika keberlanjutan sosial ditafsirkan sebagai hambatan pembangunan, maka akan terjadi penafian terhadap nilai-nilai sosial, demikan juga halnya nilai religious yang merupakan bagian dari nilai-nilai sosial di tengah masyarakat. Nilai-nilai religious Islami disebut dihimpun dalam etika bisnis Islam.

Pada penelitian terdahulu antara lain, Marzuqi and Latif (2010) menurutnya ada lima cara mengimplementasi Etika Bisnis Islam, yaitu: (1) Menerapkan konsep Iman, Islam dan Ihsan dalam berbisnis, yaitu dengan usaha sungguh-sungguh, bekerja baik

(C) 2019 by the authors; Association of Indonesian Moslem Scholar, Hannover, Germany. This is an Open Access article distributed under the terms of the Creative Commons Attribution-ShareAlike 4.0 International License. (https://creativecommons.org/licenses/by-sa/4.0/), which permits unrestricted use, distribution, and reproduction in any medium, provided the original work is properly cited. 
berdasarkan etika, dan berdedikasi penuh sehingga memperoleh hasil yang oftimal; (2) Teliti dan teratur dalam menjaga kualitas produk yang dihasilkan, mengadakan penelitian dan pengawasan kualitas sehingga hasilnya maksimal; (3) Hemat menggunakan sesuatu sesuai dengan kebutuhan, sehingga benar-benar bermanfaat; (4) Jujur dan adil dalam berbisnis akan membawa rahmat, ketentraman dan kesejahteraan sehingga keuntungan nya membawa berkah; an (5) Bekerja keras dalam menuntaskan pekerjaannya sehingga mendapatkan hasil-pahala yang lebih besar. Masalahnya, menurut Farid and Zahroh (2015) penyebab masyarakat tidak mengaplikasikan etika bisnis Islam adalah kurangnya edukasi, belum membudaya nilai etika bisnis Islam, dan adanya benturan dengan tata nilai yang berlaku di masyarakat.

Sesuai dengan pendapat Rawiworrakul, Triumchaisri, and Mawn (2010) ...our very existence at a crossroads in large part due to "western values" that have led to poorly controlled consumption of natural limited resources with limited protection of the environment. Padahal, nilai-nilai sosial dapat mempertahankan keberlanjutan lingkungan alam dan memperkokoh struktur sosial. Lebih dari itu nilai-nilai religios akan meningkatkan harmonisasi dan kesejahteraan masyarakat. Di sinilah letak pentingnya, deskripsi nilai-nilai religious dan aplikasinya dalam bisnis. Sebagai contoh empirisnya dalam komunitas bisnis kuliner di Cipacing, Cileunyi, Kabupaten Bandung, Jawa Barat. Oleh karena itu, tujuan penelitian ini adalah

1. mendeskripsikan persepsi nilai-nilai keberkahan bisnis Islam pada komunitas bisnis kuliner di Cipacing

2. mendeskripsikan konteks situasi sosial komunitas bisnis kuliner di Cipacing

\section{METODE PENELITIAN}

Agar hasil analisis diperoleh secara akurat, maka dalam penelitian ini dilakukan tiga langkah utama. Pertama, metode penyediaan data dengan teknik survei, penyebaran kuisioner, dan wawancara terpilih, lihat Mahsun (2005). Kedua, metode analisis data yang digunakan adalah pendekatan eklektika dari beberapa teori critical discourse analysis (CDA). Hasil analisis dilakukan dengan pendekatan metode kualitatif. Kemudian data diinterpretasikan sehingga didapat aplikasi keberlanjutan keberkahan komunitas bisnis kuliner (K3BK). Ketiga, metode penyajian data dengan teknik bagan prosentasi yang kemudian secara informal dijelaskan dengan kata-kata secara deskriptif sehingga diperoleh kesimpulan.

\subsection{Metode Penyediaan Data}

Metode penyediaan data dalam penelitian ini adalah metode simak-cakap. Adapun teknik yang digunakan adalah teknik survei, penyebaran kuisioner, dan wawancara responden terpilih. Persiapan penyedian data diawali dengan pembuatan instrumen penelitian. Langkahnya berupa (a) penyusunan daftar pertanyaan yang disusun sesuai dengan tujuan; (b) menguji kesesuaian daftar pertanyaan dengan kondisi responden; dan (c) memperbaiki daftar pertanyaan. Setelah data tersedia, ditatat (rekam), disusun, dan diklasifikasikan, diadaptasi dari Mahsun (2005).

\subsection{Metode Analisis Data}

Beberapa teori CDA yang digunakan dalam penelitain ini adalah critical discourse analysis. Al-Wasilah (2006) menyatakan bahwa CDA merupakan salah satu pendekatan dalam penelitian cultural studies (CS). Hal ini didukung oleh pendapat Pennycook (2001), bahwa ada delapan prinsip penting CDA. Prinsip yang sesuai dengan penelitian ini antara lain penyelesaian problem social tentang keberlanjutan nilai-nilai sosial, khususnya aplikasi nilai-nilai religious dalam komunitas bisnis kuliner.

Metode analisis penelitian ini bersifat non hipotesis. Analisis dilakukan sesuai dengan identifikasi masalah dan tujuan penelitian ini, yaitu dengan menganalisis tabel prosentasi secara deskriptif. Hal ini sesuai dengan pendapat Arikanto (2006), bahwa data prosentasi secara umum diambil berdasarkan sample dari populasi bersifat non hipotesis.

Analisis deskripsi prosentase diambil berdasarkan populasi dan sampel anggota komunitas. Populasi adalah wilayah generalisasi yang terdiri atas objek/ subjek yang memiliki kualitas dan karakteristik tertentu yang ditetapkan oleh peneliti untuk dipelajari dan kemudian ditarik kesimpulannya (Sugiyono, 2006). Dengan kata lain, menurut Arikunto (2006) populasi adalah keseluruhan subjek penelitian.

\section{HASIL PENELITIAN}

Berdasarkan hasil kuisioner dari populasi 30 orang anggota komunitsa, sampel responden penelitian ini adalah 21 pedagang. Hasil pengolahan data berdasarkan instrumen kuisioner diperoleh input, proses, dan output kuisioner. Adapun stanndar konversi tingkat keberhasilan digunakan skala prosentasi sebagai berikut: (1) 0\%-20\% (sangat rendah); (2) 21\%-40\% (rendah); (3) 41\% - 60\% (cukup); (4) 61\%- 80\% (tinggi); dan (5) 81\% - 100\% (sangat tinggi). Analisis data diperoleh dengan menganalisis jawaban responden terhadap kuisioner dengan menghtung prosentasenya. 1) / TT/ 'Tidak Tahu', 2) /STS/ 'Sangat Tidak Setuju', 3) /TS/ 'Tidak Setuju', 4) /S/ 'Setuju', 5) /SS/ ' Sangat Setuju'. Penyajian hasilnya bisa diringkas sesuai dengan kebutuhan.

Berdasarkan hasil wawancara dan pengisian kuisioner dengan para pedagang kuliner tahu Sumedang, diperoleh data sebagai berikut: Dari 30 orang anggota komunitas bisnis kuliner tahu yang mengisi data 21 orang (70\%), terdiri dari pria 9 orang (43\%) dan wanita 12 orang (57\%). Rata-rata umur pria berkisar antara 30-50 tahun, sedangkan wanita antara 19-47 tahun. Pengalaman dagang mereka yang lebih dari 15 tahun 5 orang (22\%), antara 10-15 tahun ada 9 orang (39\% ), antara 5-10 tahun ada 3 orang (13\%), dan yang kurang dari 5 tahun ada 6 orang (26\%).

Rata-rata etos kerja mereka dalam hitungan jam perhari adalah sebagai berikut: lebih dari 12 jam ada 14 orang (67\%), antara 8-12 jam ada 6 orang (28\%), sedangkan yang kurang dari 8 jam hanya 1 orang (5\% ). Berdasarkan data ini etos kerja mereka sangat tinggi yaitu 20 orang 95\%. Adapun omset (barang yang terjual setiap hari rata-rata: margin 2.5-4 jt ada 4 orang (19\%), antara 1-2 jt ada 2 orang (10 \%), sedangkan sisanya 15 orang (71\%) kurang dari 1 jt per hari.

\subsection{Persepsi Keberkahan Bisnis}

Persepsi keberkahan komunitas bisnis kuliner tahu diukur berdasarkan hasil kuisioner. Adapun unsur-unsurnya adalah 1. Keyakinan, 2. Bentuk keberkahan, 3. Persepsi etika dagang, 4.Zakat harta, 5. Dorongan menunaikan hal yang dianjurkan, 6. Kepatuhan menjauhi larangan,7. Keteguhan pada prinsip sosial, 8. Target dalam jual beli, dan 9.Peningkatan jumlah \& kualitas komoditas.

Perhatikan Tabel 1 prosentasi persepsi keberkahan komunitas bisnis kuliner 
Tabel 1. Prosentasi persepsi keberkahan komunitas bisnis kuliner

\begin{tabular}{|c|c|c|c|c|}
\hline No & Pernyataan & Aspek & SS & $\mathbf{S}$ \\
\hline 1 & Ketaatan pada hukum Allah membawa keberkahan dalam bisnis & Keyakinan & & \\
\hline 2 & $\begin{array}{l}\text { Keberkahan dapat berupa keuntungan, kesehatan, kesejahteraan, tercukupinya } \\
\text { semua kebutuhan }\end{array}$ & Bentuk keberkahan & $19 \%$ & $81 \%$ \\
\hline 3 & $\begin{array}{l}\text { Berdagang yg baik dan benar harus sesuai dengan aqad, syarat, rukun dagang } \\
\text { menurut Islam }\end{array}$ & Etika dagang & $19 \%$ & $81 \%$ \\
\hline 4 & Setiap muslim memenuhi syarat nisab wajib menunaikan zakat harta (dagang). & Zakat harta & $14 \%$ & $86 \%$ \\
\hline 5 & $\begin{array}{l}\text { Setiap muslim disunnahkan untuk bershadaqah, infak pembangunan masjid, } \\
\text { menunaikan ibadah qurban, dll yang dicontohkan Rasul Allah SAW. }\end{array}$ & Shadaqah harta & $14 \%$ & $86 \%$ \\
\hline
\end{tabular}

Pertama, keyakinan para pedagang tahu bahwa sumber keberkahan dalam berbisnis adalah ketaatan pada Allah tinggi. Berdasarkan hasil kuisioner menyatakan sangat setuju (29\%) dan setuju (71\%). Bila keyakinan bahwa rizki adalah pemberian Allah telah menjadi persepsi (mafahim) seseorang, maka perilakunya akan terbentuk sesuai dengan persepsinya. Hal ini sesuai dengan firman Allah dalam Al-Qur'an (2010) bahwa hakikat rizki adalah al-a'tha (pemberian), antara lain QS. 2: 3, yaitu /razaqnaahum/ 'Kami anugrahkan rezeki kepada mereka', QS. 2:22, yaitu /rizqal lakum/ 'rezaki untukmu'; Qs. 2:60, /min rizqi Allahi/ 'rezeki yang diberikan Allah'; QS. 2;172 ,/rajaqnaakum/ 'Kami berikan rezeki kepadamu'.

Kedua, persepsi keberkahan para pedang sangat baik. Berdasarkan hasil kuisioner menyatakan sangat setuju (19\%) dan setuju (81\%). Secara etimologi, 'keberkahan' berasal dari bahasa Arab menurut Munawwir and Fairuz (2007)/baarakabarakatan/ 'kenikmatan atau doa supaya mendapat kenikmatan dan kebahagiaan'. Adapun secara terminologi, menurut Jurjani and Al-Sharif (2014) keberkahan adalah /ziyaadatu 'l-khoer/ 'bertambahnya kebaikan'. Di sisi lain pengertian /khoer/ menurut Allāh (2002) adalah / kullu maa radha Allah/ 'segala sesuatu yang Allah ridhai'. Jadi keberkahan adalah bertambahnya kebaikan pada segala sesuatu yang Allah ridhai.

Ketiga, persepsi para pedagang dalam mengaplikasikan etika berdagang sangat baik. Perhatikan point tiga hasil kuisioner menyatakan sangat setuju (19\%) dan setuju (81\%). Adapun etika berdagang dalam Islam menurut As-Sabatin (2009) harus memenuhi rukun akad, yaitu:

1. Al-aqidani (Dua Pihak Yg Berakad)

Harus layak melangsungkan akad, yakni baligh dan berakal, atau minimal mumayyiz tapi tergantung izin dari pihak yang bertanggungjawab atasnya.

2. Mahallul Aqad (Objek Akad)

Sesuatu yang menjadi obyek akad. Misalnya barang yang dijual dalam akad bay'; utang yang dijamin dalam akad kifâlah; proyek/kegiatan bisnis untuk mendapat keuntungan dalam akad syirkah

3. Shighat Akad (Ijab Kabul)

Ungkapan timbal balik yang menunjukkan kesepakatan kedua pihak, harus dinyatakan secara jelas; Ijab dan qabul harus bertaut, dalam satu majelis. Redaksi lafzhiyah yang mengungkapkan kehendak kedua pihak dalam melangsungkan akad; Ijab harus menunjukkan kepastian. Bisa dengan ucapan, tulisan, praktek yang menunjukkan deal/kesepakatan (bi at-ta'âthâ), atau dengan isyarat.

Keempat, persepsi para pedagang untuk menunaikan kewajiban terhadap harta sangat baik. Perhatikan point empat hasil kuisioner menyatakan sangat setuju (14\%) dan setuju (86\%). Hakikat harta dalam Al-Qur'an (2010) QS. 24:33 adalah/maali Allah/ 'milik Allah'. Hanya saja, Allah menurut Abdullah (2002) membagi kepemilikan harta menjadi tiga bagian, yaitu: (1) kepemilihan individu (al-milkiyyah al-fardiyyah); (2) kepemilikan umum (al-milkiyyah al-'ammah); dan (3) kepemilikan negara (al-milkiyyah a-dawlah). Adapun diantara kewajiban individu yang memilik harta adalah berzakat serta membelanjakan harta untuk keperluan diri dan orang-orang yang menjadi tanggungjawabnya.

Kelima, persepsi para pedagang untuk menunaikan shadaqah harta sangat baik. Berdasarkan point lima hasil kuisioner menyatakan sangat setuju (14\%) dan setuju (86\%). Dalam aturan Islam, menurut Abdullah (2002) selain adanya kewajiban bagi individu yang memiliki harta, juga ada anjuran untuk bershadaqah dan saling memberi hadiah sebagai sarana silaturahmi.

Tabel 2. Prosentasi persepsi larangan ribawi

\begin{tabular}{clcc}
\hline No & & Pernyataan & Aspek \\
\hline 6 & $\begin{array}{l}\text { Riba (bunga bank, defosito, rentenir, dll) adalah haram, wajib dijauhi dan } \\
\text { ditinggalkan. }\end{array}$ & Menjauhi larangan \\
\hline
\end{tabular}

Keempat, persepsi kepatuhan para pedagang untuk menjauhi larangan bisnis sangat baik (86\%). Walaupun masih ada responden sekitar $14 \%$ yang menyatakan tidak tahu dan tidak masalah dengan riba. Menurut As-Sabatin (2009), harta riba adalah haram banyak atau sedikit sama saja. Adapun landasannya dalam Al-Qur'an (2010) QS. 278-279, terdapat kalimat imperatif /wadzaruu maa baqia mina 'r-riba/ ' tinggalkanlah sisa riba'.

Tabel 3. Prosentasi persepsi berbusana muslimah dan targe berdagang

\begin{tabular}{|c|c|c|c|c|}
\hline No & Pernyataan & Aspek & SS & $\mathbf{S}$ \\
\hline 7 & Bagi kaum muslimah ketika di luar rumah wajib mengenakan busana muslimah & Busana Muslimah & $19 \%$ & $81 \%$ \\
\hline 8 & $\begin{array}{l}\text { Target dalam berdagang mendapat keuntungan (profit) dan memberikan manfaat } \\
\text { (benefit) pada sesama manusia }\end{array}$ & Target Berdagang & $19 \%$ & $81 \%$ \\
\hline
\end{tabular}

Ketujuh, persepsi para wanita pedagang untuk mengenakan busana muslimah sangat baik. Berdasarkan hasil kuisioner menyatakan sangat setuju (19\%) dan setuju (81\%). Disarikan dari An-Nabhani (2003), persyaratan busana muslimah di luar rumah adalah (1) menutup seluruh aurat, kecuali muka dan tapak tangan; (2) tidak boleh bertabarruj (memperlihatkan perhiasannnya); (3) bahan busananya tidak tipis atau tembsu pandang, (4) mengunakan jilbab (baju kurung) dan khimar (kerudung). 
Kedelapan, persepsi para pedagang untuk mendapat keuntungan (profit) dan memberikan manfaat (benefit) pada sesama manusia sangat baik. Berdasarkan hasil kuisioner menyatakan sangat setuju (19\%) dan setuju (81\%). Menurut \{al-Haritsi, 2003 \#84@@author-year\} bahwa di antara hal penting untuk melakukan pengawasan dalam transaksi jual beli di pasar. Adapun tujuan terpenting pengawasan pasar adalah (1) terjaganya kebebasan bertransaksi sesuai Islam, sebaliknya tidak boleh ada konglomerasi pedagang tertentu terhadap yang lain; (2) terjaganya promosi berdasarkan kejujuran dan amanah sehingga tercipta suasana investasi yang kondusif; (3) menjaga stabilitasi harga, menghindari hal-hal penyebab inflasi.

Tabel 4. Prosentasi persepsi menabung

\begin{tabular}{|c|c|c|c|c|}
\hline No & Pernyataan & Aspek & $\mathbf{S S}+\mathbf{S}$ & TS \\
\hline 9 & Menabung untuk meningkatkan jumlah dan jenis barang & Menabung & $90 \%$ & $10 \%$ \\
\hline
\end{tabular}

Kesembilan, persepsi para pedagang untuk menabung untuk meningkatkan jumlah dan jenis barang adalah baik. Walaupun masih ada responden $10 \%$ yang tidak setuju dengan menabung. Padahal, Nabhany membedakan istilah menabung /idkhar/ dan menimbun /kanzun/\{An-Nabhany, 2002 \#87@@author-year\}. Hukum manabung boleh, sedangkan hukum /kanzun/ 'menimbun uang, emas, perak' adalah haram. Berdasarkan tabel-tabel tersebut ada dua hal yang perlu perhatian, yaitu peningkatan jumlah dan kualitas barang dagangan serta pembinaan keteguhan terhadap persepsi baik dalam pelaksanaan etika berdagang dan menjauhi larangan terlibat riba.

\subsection{Critical Discourse Analysis}

Fairclough (2000) menawarkan analisis tiga dimensi. Dimensi pertama, (tingkat mikro) analisis tekstual yaitu mendeskripsikan apa yang terdapatdalam sebuah teks. Kedua, tingkat meso adalah interpretasi proses wacana dan teks. Dimensi ketiga, praktik sosial (level makro) adalah menjelaskan hubungan proses wacana dan proses sosial. Dalam penelitian ini, penulis memfokuskan pada dimensi ketiga, praktik sosialkultural.

Dalam dimensi praktik sosiokultural, penulis mengadopsi analisis tingkat makro pada tataran genius lokal. Kearifan (atau kebijaksanaan) dalam bahasa Arab dikenal sebagai hikmah, yaitu Al-ma'rifatu 'l-kamilatu likuli ma yastathi'u 'l-insan an ya'rifa litadbiri hayati au lihifzhi shihhathi Badawi (1993) artinya pengetahuan sempurna yang mendukung kemampuan manusia untuk menyadari dan berusaha menjaga kesehatan fisik dan mental mereka.Kearifan lokal dalam penelitian ini didefinisikan sebagai upaya manusia untuk bertindak dan memiliki sikap objektif pada setipa peristiwa melalui kognisi dan enkulturasi. Salah satu kearifan lokal dalam upaya mengelola keuangan dalam komunitas adalah arisan.

Fairclough (1992) mengungkapkan bahwa dalam analisis wacana, seorang peneliti harus memastikan dan menjelaskan kausalitas praktik sosial dan hubungannya dengan struktur sosial dan budaya dalam teks seperti perubahan praktik sosial, pengetahuan dan nilai-nilai, hubungan, identitas, dan sebagainya. Namun, Fairclough (1992) mengakui bahwa praktik sosial tidak mudah untuk ditentukan. Oleh karena itu, ia menyarankan bahwa praktik sosial dianalisis melalui beberapa tingkatan organisasi sosial seperti (1) konteks situasional, (2) konteks kelembagaan, dan (3) konteks sosial.

\subsection{Konteks Situasi}

Komunitas bisnis kuliner tahu Sumedang berada di desa Cipacing, kecamatan Cileunyi. Kawasan ini merupakan ujung jalan tol Cileunyi, sehingga situasi jalannya 24 jam ramai. Di pinggir jalan perempatan terdapat masjid al-Musyawarah. Sehingga wajar etos kerja para pedagang melakukan aktivitasnya setiap hari 24 jam. Biasanya, mulai pagi sampai sore yang berdagang adalah kaum

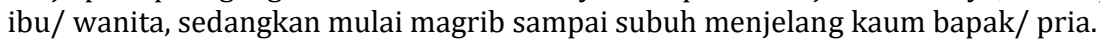

Komunitas bisnis kuliner tahu sumedang desa Cipajing dalam penelitian ini berjumlah 30 orang. Mereka melakukan kegiatan bersama berupa arisan. Arisan ini sebagai sarana bertemu dan saling membantu secara finansial. Penarikan uang dilakukan perminggu. Beberapa saran dari anggotanya antara lain: agar diadakan semacam pengarahan bisnis dan pengajian bulanan sebagai bentuk pembinaannya.

Mereka termotivasi dengan kisah sukses Fuad Affandi, beliau berhasil menyulap desa minus menjadi desa surplus. Pimpinan pondok pesantren Al-Ittifaq dengan 300 santri ini memelopori bisnis pertanian di desa miskin Alam Indah dan Lebak Muncang, Kecamatan Ciweday, Kabupaten Bandung, hingga mampu menjadi desa surplus dengan hasil sayuran tak kurang dari lima ton setiap harinya. Kesempatan bisnis itu didapatkannya setelah ia dengan kelompok taninya Al-Ittifaq menjadi satu-satunya pesantren yang menyanggupi tantangan pasar swalayan Hero untuk mendapatkan pasokan sayuran segar dari pesantren tatkala mengikuti pertemuan bisnis di Yayasan Prasetyamulya, Jakarta tahun 1993. Kini, dua desa itu memonopoli pengadaan sayuran segar di Pasar swalayan utama Bandung dan Jakarta. Vegetable storeage Hero dan Makro dipenuhi sayuran Ciweday, mulai wortel, buncis, kentang, mentimun Jepang, dan aneka bawang.

\subsection{Konteks Sosial}

Konsep social sustainability muncul sebagai kelanjutan konsep economic sustainability dan environmental sustainability. Konsep ini muncul dalam pertemuan di Yohannesberg pada tahun 2002 yang dilatarbelakangi argumetasi berikut: 1) konsep economic sustainability dan environmental sustainability belum dapat mengangkat kesejahteraan komunitas di negara-negara di dunia; 2) perlunya suatu tatanan aturan untuk menyeimbangkan kesejahteraan pembangunan di negara-negara maju dan negara-negara berkembang.

Pemerintah Indonesia berkomitmen mendukung pengembangan Sustainable Development Goals (SDGs), dan komitmen itu antara lain diwujudkan melalui program dalam dokumen Rencana Pembangunan Jangka Menengah Nasional (RPJMN) yang disusun oleh Bappenas. Namun, implementasinya masih belum terjadi di lapangan. Unpad.ac.id, 29/09/2015 diakses 4 April 2016.

Guru besar Fakultas Ilmu Sosial dan Ilmu Politik (FISIP) Unpad, Prof. Oekan S. Abdoellah, M.A., PhD mengatakan, "Kalau kita bicara mainstreaming sustainable development, itu sudah ada di RPJMN. Tapi faktanya tidak semakin membaik. Kerusakan lingkungan malah semakin memburuk" . Diskusi Terbatas Kompas-Unpad "Tantangan Implementasi Gagasan Pembangunan Berkelanjutan dalam Perspektif Nasional \& Daerah"di Ruang Rapat Redaksi Gedung Kompas Gramedia, Jakarta, Selasa (29/09).

Mantan Menteri Perencanaan dan Pembangunan Nasional/Kepala Bappenas 2009-2014 ini mengatakan, tujuan utama dari pembangunan berkelanjutan harus dapat diterjemahkan ke dalam target yang nyata. Sinergi kolaborasi antara pemerintah pusat, 
provinsi, hingga kabupaten dan kota sangat penting dilakukan. Terkait solusi yang ditawarkan, Prof. Oekan juga menilai komitmen politik pemerintah terkait pembangunan harus mengimplementasikan pembangunan berkelanjutan.

Jawa Barat, propinsi yang jumlah penduduknya terbesar di Indonesia. Bentang alam yang luas dengan lokasi ekonomi strategis. Tanahnya subur untuk berbagai kegiatan pertanian. Pusat dari pengembangan ilmu, teknologi dan pendidikan. Walaupun dengan potensi seperti diatas, pencapaian pembangunan di Jawa Barat ternyata masih sub-optimal yang ditunjukkan dengan Indeks Pembangunan Manusia (IPM) Jawa Barat yang masih berada di bawah rata-rata nasional.

Ketika pertumbuhan ekonomi tinggi tidak disertai dengan peningkatan kesejahteraan yang proporsional, ini mengindikasikan bahwa pertumbuhan ekonomi, proses dan manfaatnya belum tersebar relatif merata karena permasalahan sosial dan institusional. Ini indikasi bahwa investasi dalam peningkatan modal sosial (social capital) tidak terjadi sesuai potensinya.

Proses pembangunan yang dilakukan Pemkab Bandung bersama masyarakat selama 2010-2015, tentunya berpijak kepada Visi dan Misi Pembangunan yang telah ditetapkan. Adapun visi pembangunan Kabupaten Bandung, yaitu "Terwujudnya Kabupaten Bandung yang maju, mandiri dan berdaya saing, melalui tatakelola pemerintahan yang baik dan pemantapan pembangunan perdesaan, berlandaskan religius, kultural dan berwawasan lingkungan.

Sedangkan misi yang diemban untuk mewujudkan visi tersebut, terdapat 7 (tujuh) diantaranya, (1) Meningkatkan profesionalisme birokrasi; (2) Meningkatkan kualitas SDM; (3) Memantapkan pembangunan perdesaan: (4) Meningkatkan keamanan dan ketertiban wilayah; (5) Meningkatkan ketersediaan infrastruktur dan keterpaduan tata ruang wilayah; (6) Meningkatkan ekonomi kerakyatan yang berdaya saing; (7) Memulihkan keseimbangan lingkungan dan menerapkan pembangunan berkelanjutan.

Dengan mengacu kepada Visi dan Misi tersebut, Badan Pusat Statistik (BPS) Kabupaten Bandung dan Bappeda Kab. Bandung menghitung hasil pembangunan yang dicapai Kabupaten Bandung sampai akhir tahun 2012 menunjukan angka yang meningkat. Hal ini terbukti dengan pencapaian IPM (Indeks Pembangunan Manusia) tahun 2012 sebesar 75,24, naik dibanding tahun 2011 sebesar 74,44 .

\section{Pembahasan}

Berdasarkan data dan analisis situasi dan konteks sosial agar komunitas bisnis berlanjut dalam keberkahan diperlukan hal-hal sebagai berikut.

\subsection{Profesionalisme kerja}

Nilai-nilai religious dalam profesionalisme kerja adalah:

(1) Kafa'ah, kecakapan/ keterampilan, memiliki ilmu pengetahuan dalam bisnis diperoleh melalui pendidikan, pelatihan, dan pengalaman.

(2) Himmatul 'amal, target dan etos kerja yang tinggi diraih dengan jalan motivasi beribadah sebagai pendorong utama dalam berbisnis disamping motivasi mendapatkan penghargaan (reward) dan menghindari hukuman (punishment)

(3) Amanah diperoleh dengan menjadikan tauhid sebagai unsur pengontrol utama tingkah laku. Hal ini sesuai dengan sabda Nabi Muhammad saw antar lain : (a) Tidak beriman orang yang tidak menjaga amanah dan (dianggap) tidak beragama orang yang berkhianat (HR ad-Dailami); (b) Tunaikan amanah terhadap orang yang mengamanahimu dan jangan berkhianat terhadap orang yang mengkhianatimu (HR Ahmad dan Abu Dawud).

\subsection{Manajemen Amanah dalam bisnis}

Sikap amanah wajib dimiliki seorang pedagang/ pembisnis muslim. Sikap ini bisa dimiliki jika seseorang selalu menyadari bahwa apa pun aktivitas yang dilakukan selalu diketahui oleh Allah (ihsan). Sikap amanah dapat diperkuat dengan selalu meningkatan pemahaman Islam dan istiqamah menjalankan hukum-hukum Allah. Sikap amanah juga dapat dibangun dengan jalan saling menasehati dalam kebajikan serta mencegah berbagai penyimpangan.

Manejeman amanah dalam bisnis antara lain dapat dilakukan dengan menyadari manajemen proses bisnis bahwa input berupa material, tenaga kerja, informasi dan modal adalah amanah. Maka dalam manajemen proses dan strategi SDM, operasional, keuangan dan pemasarannya menjauhkan dari berbagai penyelewengan seperti; (1) tidak memberi hadiah/ komisi dalam lobi bisnis (uang, wanita dll) sebagai suap; (2) tidak terlibat ribawi; (3) tidak wan-prestasi/ ingkar janji; (4) input proses dan out proses terbebas dari barang dan jasa haram; tidak menipu, tidak korupsi, dang tidak berbuat dzalim. Sehingga out put bisnisnya berupa barang dan jasa yang tinggi kualitas dan kuantitasnya.

\subsection{Keimanan dan ketaqwaan penyebab keberkahan}

Berdasarkan analisis pada teks Al-Qur'an yang berkaitan dengan tema keberkahan ditemukan ada 19 ayat keberkahan. Secara

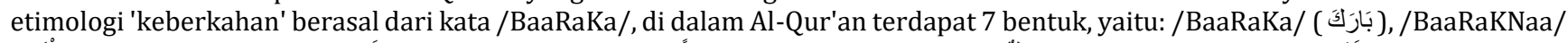

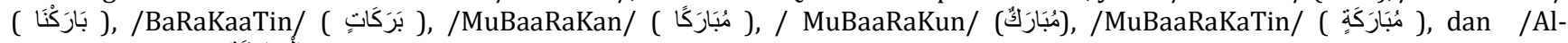
MuBaaRaKaTi/ (الْمَبَاركَكَة). Dalam Al-Qur'an ada empat tema 'keberkahan', yaitu: (1) Mengimani Al-Qur'an dan mengamalkannya; (2) semua tempat orang yang beriman-bertaqwa, dan saling mendoakan; (3) Mu'jizat para Nabi; dan (4) mengikuti Sunnatu Allah. Adapun rincian tema keberkahan dalam Al-Qur'an, perhatikan tabel 5, Tema keberkahan dalam Al-Qur'an 
Tabel 5. Tema keberkahan dalam Al-Qur'an

\begin{tabular}{|c|c|c|}
\hline No & Surat, ayat Al-Qur'an & Tema \\
\hline 1 & QS. Fushilat, 41:10 & $\begin{array}{l}\text { Allah menciptakan gunung dan memberkahinya dengan berbagai } \\
\text { tanaman yang bisa dimakan }\end{array}$ \\
\hline 2 & QS. Al-A'raf, 7:137 & $\begin{array}{l}\text { Allah mewariskan tanah syam dan Mesir yang diberkahi kepada kaum } \\
\text { yg dulu tertindas }\end{array}$ \\
\hline 3 & QS. Al-Isra', 17:1 & Masjid Al-Aqsha, Palestina tanah yang diberkahi \\
\hline 4 & QS. Al-Anbiya, 21:71 & $\begin{array}{l}\text { Allah menyelamatkan Nabi Nuh dan Lut di negeri yang diberkahi (Syam, } \\
\text { Palestina) }\end{array}$ \\
\hline 5 & QS. Al-Anbiya, 21:81 & $\begin{array}{l}\text { Allah memberikan mu'jizat kepada Nabi Sulaiman dengan } \\
\text { mengendalikan angin menuju negeri yang diberkahi }\end{array}$ \\
\hline 6 & QS. Saba', 34: 18 & Syam, negeri yang diberkahi Allah \\
\hline 7 & QS. Al-A'raf, 7:96 & Penyebab keberkahan adalah keimanan dan ketaqwaan kepada Allah \\
\hline 8 & QS. Ali Imran, 3: 96 & Baitu Allah, Makkah diberkahi Allah \\
\hline 9 & QS. Maryam, 19:31 & Nabi Isa A.S diberkahi Allah (karena Taqwa) \\
\hline 10 & QS. Al-Mu'minun,23: 29 & Keberkahan tempat tujuan dengan berdoa \\
\hline 11 & QS. Qaaf, 50: 9 & Keberkahan air hujan \\
\hline 12 & QS. Al-An'am, 6: 92 & Keberkahan Kitab Suci, Al-Qur'an \\
\hline 13 & QS. Al-An'am, 6: 155 & $\begin{array}{lllll}\begin{array}{l}\text { Keberkahan Kitab } \\
\text { (mengamalkannya) }\end{array} & \text { Suci, } & \text { Al-Qur'an } & \text { dengan } & \text { mengikutinya } \\
\end{array}$ \\
\hline 14 & QS. Al-Anbiya, 21: 50 & Keberkahan Kitab Suci, Al-Qur'an sebagai peringatan \\
\hline 15 & QS. Shaad, 38: 29 & Keberkahan Kitab Suci, Al-Qur'an dengan dihayati \\
\hline 16 & QS. An-Nur, 24: 61 & Keberkahan rumah ketika memasukinya dengan salam (doa) \\
\hline 17 & QS. Ad-Dukhan, 44: 3 & Malam lailatul Qadr malam keberkahan \\
\hline 18 & QS. An-Nur, 24: 35 & Pohon zaitun pohon keberkahan \\
\hline 19 & QS. Al-Qashash, 28: 30 & Tanah yang diberkahi tempat Nabi Musa diangkat menjadi Rasul \\
\hline
\end{tabular}

\section{KESIMPULAN}

Berdasarkan temuan hasil dan pembahasan, maka dapat disimpulkan ada dua hal penting, Pertama terdeskripsikan nilai-nilai keberkahan bisnis dalam komunitas bisnis kuliner Cipacing, yaitu: 1. Adanya keyakinan yang kuat, bahwa Allah pemberi rizki, 2. Memahami ragam bentuk keberkahan dalam kehidupan, 3. Memahami dan mengamalkan etika dagang Islam, 4. Membayarkan zakat harta, 5. Termotivasi menunaikan hal yang sunnah, 6. Adanya kepatuhan menjauhi larangan,7. Adanya keteguhan pada prinsip-prinsip social yang disepakati. Kedua, terdeskripsikan konteks situasi sosial pada komunitas bisnis kuliner di Cipacing. Adapun rekomendasinya, diperlukan revitalisasi nilai-nilai religious dalam aplikasi bisnis di komunitas bisnis kuliner masyarakat kabupaten Bandung. Bentuknya dapat berupa pelatihan menejeman bisnis atau pengajian bisnis Islami.

\section{Daftar Pustaka}

Abdullah, M. H. (2002). Studi Dasar-dasar Pemikiran Islam. Bogor: Pustaka Thariqul Izzah.

Al-Qur'an, S. (2010). Al-Qur 'anulkarim: Terjemah Tafsir per Kata. Bandung: Sygma Publishing.

Al-Wasilah, A. (2006). Chaidar, Pokoknya Kualitatif: Dasar-Dasar Merancang dan Melakukan Kualitatif: Jakarta: Pustaka jaya.

Allāh, M. H. A. (2002). Mafahim Islamiyah: menajamkan pemahaman Islam: Al-Izzah.

An-Nabhani, T. (2003). an-Nizham al-Ijtima'I fi al-Islam: diterjemahkan M. Nashir dkk, Sistem Pergaulan Dalam Islam, Bogor: Pustaka Thariqul Izzah.

Arikanto, S. (2006). Metode Penelitian Suatu Pendekatan Praktis. Jakarta: PT. Bina Aksara. 
As-Sabatin, Y. (2009). Bisnis Islam Dan Kritik Atas Praktik Bisnis Ala Kapitalis: Bogor, Al-Azhar Press.

Badawi, A. Z. (1993). A dictionary of the social sciences: English-French-Arabic with an Arabic-English glossary and a French-English glossary: Librairie du Liban.

Chiu, R. L. (2004). Socio-cultural sustainability of housing: a conceptual exploration. Housing, theory and society, 21(2), 65-76.

Fairclough, N. (1992). Discourse and social change (Vol. 10): Polity press Cambridge.

Fairclough, N. (2000). Critical analysis of media discourse. Media studies: A reader, 308-325.

Jurjani, A. I. M., \& Al-Sharif, A.-S. (2014). Kitab al-Ta'rifat: Al-Hakawati.

Kates, R. W. (2018). What is sustainable development?

Mahsun, M. (2005). Metode penelitian bahasa: tahapan strategi, metode dan tekniknya: PT RajaGrafindo Persada.

Marzuqi, A. Y., \& Latif, A. B. (2010). Manajemen Laba dalam Tinjauan Etika Bisnis Islam. Jurnal Dinamika Ekonomi \& Bisnis, 7(1).

Munawwir, A. W., \& Fairuz, M. (2007). Al Munawwir: kamus Indonesia-Arab: Pustaka Progressif.

Pennycook, A. (2001). Critical applied linguistics: A critical introduction: Routledge.

Rawiworrakul, T., Triumchaisri, S., \& Mawn, B. (2010). Promoting cultural sustainability in the context of public health: A thai perspective. Sustainability, 2(8), 2707-2718.

http://www.unpad.ac.id/2015/09/isu-pembangunan-berkelanjutan-di-indonesia-masih-sebatas-retorika/ accesssed on 4 April 2018

http://www.jabarprov.go.id/index.php/pages/id/1343 accesssed on 4 April 2018

http://www.bandungkab.go.id/arsip/3285/ accesssed on 4 April 2018 